\title{
A New Method for the Evaluation of Antiviral Agents agains Infectious Hematopoietic Necrosis Virus (IHNV) on Microtiter Plates: CPE Spot Reduction Method
}

\author{
Masahide HaSOBE* and Mineo SANEYOSHI* \\ (Accepted December 3, 1984)
}

\begin{abstract}
A convenient method for the evaluation of potential antiviral agents against non-segmented negative single strand RNA viruses using infectious hematopoietic necrosis virus (IHNV) in chinook salmon embryo (CHSE-214) cells was performed on microtiter plates with 96 wells. In this system, cytopathic effect (CPE) induced by IHNV infection was detected as clear spots (CPE spot) in CHSE-214 cell monolayers three days after infection. In none of the cases tested, did the standard error for the number of CPE spots per well exceed $10 \%$. This newly developed method was successfully applied to the quantitative evaluation of several antiviral agents against IHNV on microtiter plates (CPE spot reduction method), with a reproducibility equal to the plaque reduction method.
\end{abstract}

Infectious hematopoietic necrosis virus (IHNV) ${ }^{1,2)}$ belongs to rhabdovirus ${ }^{3-8)}$ which resembles Rabies virus ${ }^{7,8)}$ bearing non-segmented negative strand virus that contains single strand RNA genome. It is well known that IHNV is causual agent of severe epizootic with high mortality for salmonid fingerlings. ${ }^{1)}$ The treatment of ova with iodophors may be a sole method as a control of IHNV and it has usually advocated and employed."

While antiviral chemotherapy using nucleoside analogues such as Virazole ${ }^{\text {) }}$ and Acyclovir ${ }^{10)}$ have also recently developed and some of the compounds are found to be effective against virus diseases. In the case of fish viruses, some of the antiviral agents against infectious pancreatic necrosis virus (IPNV) ${ }^{11,12)}$ and Oncorhynchus masou virus (OMV) ${ }^{13,14)}$ have been used in vitro and in vivo.

In order to determine the antiviral effects of the compounds in vitro, it has been employed the plaque reduction method ${ }^{15-17)}$ or cytopathic effect (CPE) inhibition method ${ }^{18)}$ on microtiter plates having 96 flat-bottomed wells described by SIDWELL and HUFFMAN. The former method is well established procedure with excellent reproducibility and quantitatively. However, it requires a rather large number of cell culture and laborious workup. The later method determined with the visual scoring ( 0 to 4,0 : normal cells, 4 : virtually complete destructure of cell layers) of
CPE suppression should be difficult to compare the nearly effective compounds.

In this paper, we describe that CPE induced by IHNV infection in chinook salmon embryo (CHSE214) cell monolayers after three days post-infection (p.i.) can be detected as a clear spot (CPE spot assay) and the number of these CPE spots in a well of the microtiter plate can be counted quantitatively. Furthermore, we report that the antiviral activity of compounds in CHSE-214 cells infected with IHNV can be quantitatively evaluated by the reduction of CPE spots on microtiter plates (CPE spot reduction method).

\section{Materials and Methods}

\section{Virus and Cell Cultures}

Infectious hematopoietic necrosis virus (IHNV) was kindly supplied from T. KIMURA, Faculty of Fisheries, Hokkaido University. The stock virus was passaged five times through CHSE-214 cells $^{10}$ ) and propagated in same cell lines and used through our present study. The cells were grown in Eagle's minimum essential medium (MEM) supplemented with $10,5,2 \%$ fetal bovine serum (FBS), and $\mathrm{pH}$ was adjusted to 7.4 with $14 \mathrm{mM} \mathrm{N}$-2hydroxyethylpiperazine- $N^{\prime}-2$-ethanesulfonic acid (HEPES) and $8.9 \mathrm{mM}$ sodium bicarbonate (HEPES-MEM-10, 5 , or 2).

A plastic culture tray with 24 wells $(16 \mathrm{~mm}$ diameter) (Costar, Mass. U.S.A.) was used for the

* Division of Medicinal Chemistry, Faculty of Pharmaceutical Sciences, Hokkaido University, Sapporo 060, Japan. (羽曾部正豪・実吉蓈: 北海道大学薬学部). 
preparation of macrocultures. A microtiter plate with 96 flat bottomed circular wells (Costar, Mass. U.S.A.) was used for the preparation of microcultures.

From a cell suspension of $10^{5.7}$ cells per $\mathrm{m} /$ (in HEPES-MEM- 5 ), $0.5 \mathrm{~m} l$ was transferred into each well of plastic culture trays and $0.1 \mathrm{~m} l$ was added into each well of microtiter plates. After two days' incubation at $15^{\circ} \mathrm{C}$, nearly confluent monolayers were formed.

\section{Antiviral Agents}

Antiviral agents used for the present study were 9-(S)-(2,3-dihydroxypropyl)adenine [(S)-DHPA] which was kindly provided by A. HoLY, Czechoslovak Academy of Sciences, 7-chloro-4(4-diethylamino-1-methyl-butylamino)-quinoline (Chloroquine) (Sigma), and 1- $\beta$-D-ribofuranosyl-1,2,4,triazole-3-carboxamide (Virazole) (Yamasa shoyu, Co. Ltd).

\section{CPE Spot Assay}

Micro- and macro-culture were used for the CPE spot assay. After two days' incubation, the growth medium was discarded by aspiration from each well. And virus solution was inoculated $0.05 \mathrm{ml}$ per well of each culture. After the adsorption at $15^{\circ} \mathrm{C}$ for $1 \mathrm{~h}$, inoculum was completely removed by aspiration and maintenance medium (HEPES-MEM-2) was added $0.1 \mathrm{~m} l$ per well for microcultures and $0.5 \mathrm{ml}$ per well for macrocultures. Then the sealed culture plates were incubated at $15^{\circ} \mathrm{C}$. After three days p.i., the cultures were fixed with $30 \%$ formalin and stained with $0.1 \%$ crystal violet. Then the CPE spots were counted through the microscope.

\section{Plaque Assay}

IHNV was plaqued in CHSE-214 cell monolayers on macrocultures with a slightly modification of the procedure described by WoLF and QuimBy. ${ }^{20)}$ In this assay, we used a low gelling temperature agarose (LGT agarose, Nakarai Kagaku Co. Ltd.) to avoid the thermal damage by agarose. And $0.75 \mathrm{ml}$ of HEPES-MEM- 5 containing $1 \%$ LGT agarose was added into a well of macrocultures on a cooling plate in an ice bath. Cultures were incubated at $15^{\circ} \mathrm{C}$ for seven days after post-infection, and plaques formed by IHNV were fixed and stained as described above, and were counted through the microscope.

\section{Antiviral Experiment}

Compounds used for the evaluation of the anti- viral activity against IHNV were [S]-DHPA, ${ }^{21-28)}$ Virazole, ${ }^{\text {p) }}$ and Chloroquine. ${ }^{24)}$ Antiviral activities of the three compounds were compared with the CPE spot reduction assay and the standard plaque reduction assay as described below.

CHSE-214 cell monolayers obtained after two days' incubation of micro- and macrocultures were inoculated and were adsorbed with IHNV by similar fashions described in CPE spot assay. The viral inoculum was used in a concentration forming CPE spots or plaques of about 80 to 150 per well. After inoculum was discarded by aspiration, test compounds were added to appropriate wells. Test compounds were diluted in one-half $\log$ dilution, with $1 \mathrm{mg}$ per $\mathrm{ml}$ being maximum concentration. At the CPE spot reduction assay, compounds were diluted in HEPES-MEM-2 and added $0.1 \mathrm{~m} l$ per well of microtiter plates. In the case of the plaque reduction assay, the compounds were diluted in double strength HEPES-MEM-5 and mixed with equal volume of $2 \%$ LGT agarose before its use and were added $0.75 \mathrm{~m} l$ per well of plastic culture trays. Each experiment was contained toxicity controls (with or without test compound) and virus controls (with virus). The plates were then resealed and were incubated for three days (CPE spot reduction assay) and for seven days (plaque reduction assay). After that, fixed and stained cell sheets were counted the number of CPE spots or plaques through the microscope. And the counts were expressed as a percent of the number obtained from virus controls.

The typical layout for the CPE spot reduction assay in the microtiter plates was used the method

Table 1. Scheme of CPE spot reduction method on microtiter plates

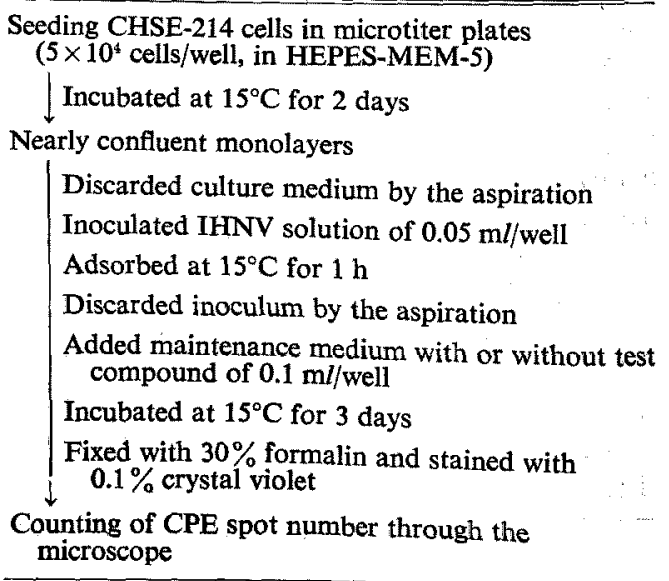


described by Sidewell and Huffman. ${ }^{18)}$

The scheme of CPE spot reduction method using microtiter plates was shown in Table 1 .
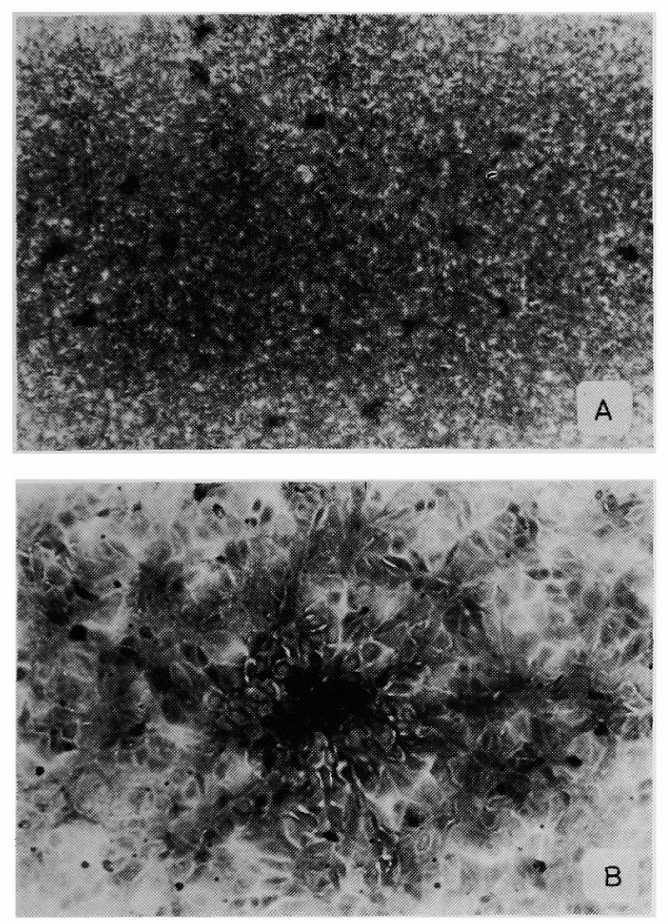

Fig. 1. CPE spots formed in CHSE-214 cell monolayers on microtiter plates. The cell sheets were fixed, and stained with crystal violet three days after infection with IHNV. A: $50 \times$ magnification, fifteen CPE spots can be observed in this figure. B: $100 \times$ magnification. A lump of rounded cells formed by IHNV infection show the focus-like CPE.

\section{Results}

\section{CPE Spot Formation by IHNV}

CHSE-214 cell monolayers infected with IHNV as described in CPE spot assay showed clear spots of CPE after three days p.i.. As can be seen in Fig. 1, these CPE spots stained with crystal violet could be discerned through a microscope at $50 \times$ magnification.

The efforts were made to achieve optimum conditions for the formation of the CPE spots. The initial cell concentration for the preparation of cell monolayers and $\mathrm{pH}$ of maintenance media were found to be important. The use of initial cell concentration around $10^{5.7}$ cells per $\mathrm{m} /$ resulted in the formation of easily countable CPE spots on

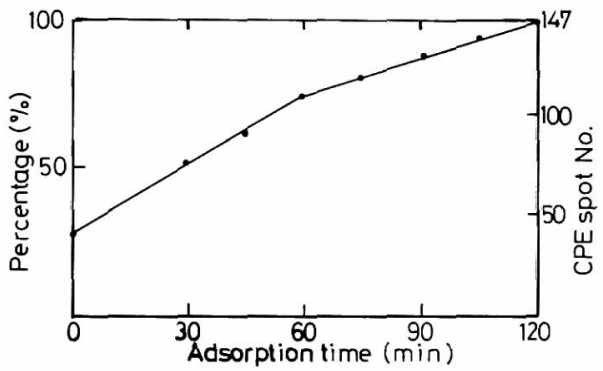

Fig. 2. Influence of the adsorption time at $15^{\circ} \mathrm{C}$ on microtiter plates for CPE spot assay. Nearly confluent CHSE-214 cell monolayers on microtiter plates were inoculated of $0.05 \mathrm{~m} l$ per well of virus suspension, and were allowed to adsorb for each period at $15^{\circ} \mathrm{C}$, and were formed $\mathrm{CPE}$ spot. The numbers of CPE spots with each adsorption time were calculated as a average of eight wells.

Table 2. Comparision of standard error between CPE spot method and plaque method

\begin{tabular}{|c|c|c|c|c|c|c|c|c|}
\hline Method & Culture & Test & Well no. & $\begin{array}{l}\text { Average } \\
(\bar{x})\end{array}$ & Max. & Min. & $\begin{array}{l}\text { Standard } \\
\text { deviation } \\
(\sigma)\end{array}$ & $\begin{array}{l}\text { Standard } \\
\text { error } \\
(\sigma / \overline{\mathrm{x}} \text { in } \%)\end{array}$ \\
\hline \multirow{8}{*}{ CPE spot } & \multirow{6}{*}{ Micro*1 } & $\mathrm{I}$ & 8 & 39.3 & 43 & 36 & 3.2 & 8.1 \\
\hline & & II & 12 & 88.8 & 98 & 82 & 4.6 & 5.2 \\
\hline & & III & 12 & 94.5 & 107 & 82 & 8.1 & 8.6 \\
\hline & & IV & 12 & 98.8 & 107 & 92 & 4.7 & 4.8 \\
\hline & & V & 12 & 104.6 & 108 & 95 & 4.2 & 4.0 \\
\hline & & VI & 8 & 147.8 & 154 & 141 & 4.3 & 2.9 \\
\hline & \multirow[t]{2}{*}{ Macro*2 } & I & 7 & 140.0 & 149 & 125 & 7.5 & 5.4 \\
\hline & & II & 5 & 137.2 & 144 & 127 & 6.1 & 4.5 \\
\hline \multirow[t]{2}{*}{ Plaque } & \multirow[t]{2}{*}{ Macro*z $^{* 2}$} & I & 7 & 120 & 139 & 103 & 10.0 & 8.4 \\
\hline & & II & 5 & 149.3 & 153 & 128 & 13.0 & 8.7 \\
\hline
\end{tabular}

*1 Microtiter plate with 96 wells. Tests (I-VI) were performed by the use of each different concentration of IHNV inoculum.

*2 Plastic culture tray with 24 wells. The both CPE spot assay and plaque assay using macrocultures were examined by the use of same concentration of IHNV solution at the same time. 


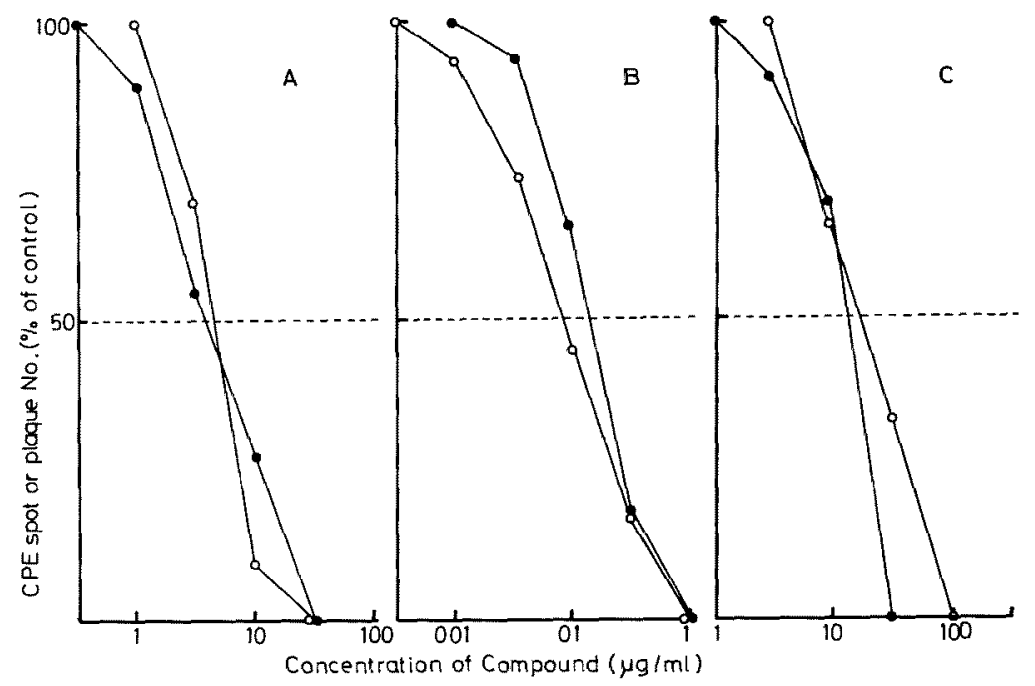

Fig. 3. Comparision of the reduction profiles obtained from CPE spot reduction method and plaque reduction method. Three compounds, A: $(S)$-DHPA, B: Virazole, C: Chloroquine, were examined the anti-IHNV activity by CPE spot reduction method using microtiter plate with 96 wells (-) and standard plaque reduction method using plastic culture tray with 24 wells (16 mm diameter) $(0-0)$.

the microtiter plate (data not shown). In addition, the use of HEPES-MEM adjusted to $\mathrm{pH} 7.4$ with $\mathrm{NaHCO}_{3}$ plus HEPES offered the more homogeneous results of CPE spots (data not shown).

\section{Quantitative Aspects of CPE Spot Counting}

Quantitative aspects of CPE spots counting were compared with the CPE spot assay in microcultures and the standard plaque assay in macrocultures. The standard error $[\sigma / \sqrt{\mathrm{x}}$ in $\%]$ was calculated from average $[\bar{x}]$ and standard deviation $[\sigma]$. As summerized in Table 2, the standard error for the number of CPE spots per well in microcultures was calculated within $10 \%$. This finding was comparable to the standard error of the standard plaque assay.

Another experiments were performed to examine the influence of the adsorption time at $15^{\circ} \mathrm{C}$ in microtiter plates of CPE spot assay. As shown in Fig. 2, the number of CPE spots by CPE spot assay increased linearly depending on the adsorption period. However, a plateau of viral adsorption was not shown within $120 \mathrm{~min}$, and the increasing ratio in the adsorption period of more than $60 \mathrm{~min}$ was lower than that of less than 60 min.

\section{Antiviral Experiment}

To evaluate our novel method (Table 1) using

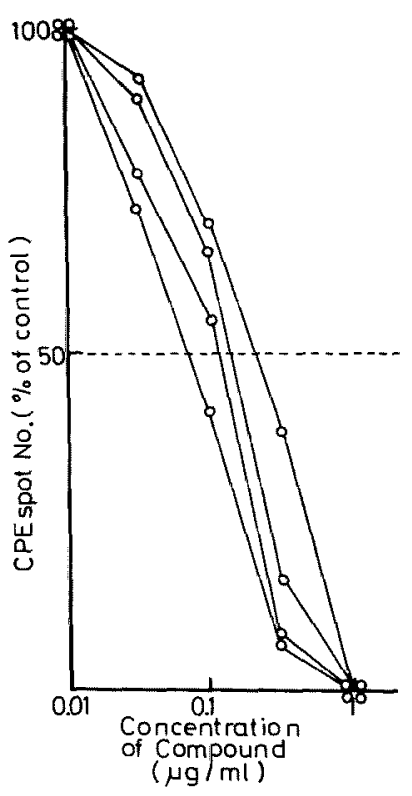

Fig. 4. Reproducibility of CPE spot reduction method on microtiter plates. Differences among four tests with Virazole were compared.

microtiter plates, we studied the practical antiviral assay of selected compounds being thought to have each different mechanism of the inhibition against viral growth.

The profiles of the CPE spot reduction curve 
obtained in microcultures were compared with that of plaque reduction curve. As can be seen in Fig. 3, very similar reduction curves and $50 \%$ inhibitory concentration $\left(\mathrm{IC}_{\mathrm{s} 0}\right)$ values were obtained from the assay of each compounds tested by two methods.

The additional test was carried out for the reproducibility of our method. Differences among four tests using CPE spot reduction method with Virazole were compared. As shown in Fig. 4, almost identical profiles, $\mathrm{IC}_{\mathrm{b} 0}$, and minimum inhibitory concentration (MIC) values were obtained respectively. These finding showed the definite reproducibility of our method.

\section{Discussion}

The procedure of plaque formation of IHNV were reported from some laboratories. ${ }^{20,28)}$ As described by DoBOs, ${ }^{25)}$ there are possibility that a certain fish cell lines should be damaged thermally by agarose overlay and the plaques result unacceptable variation. In the case of antiviral assay for the candidate compounds, we so used LGT agarose to avoid the thermal damage. This modification has successfully applied to the evaluations of antiviral agents of IHNV infection by the plaque reduction method. However, this method requires a rather large number of cell cultures and laborious workup.

As part of our program on the design and synthesis of nucleoside analogues having antiviral and antitumor activities, the synthesis of potential anti-RNA viral agents was undertaken. In such situation, we therefore needed the simple, rapid and less expensive method for the screening of relatively small quantities of newly synthesised nucleoside analogues. So we tried to establish a simplified procedure for the antiviral screening using microtiter plates with 96 wells.

The fixed and stained CPE on CHSE-214 cell monolayers after three days p.i. was shown as visible clear spots (Fig. 1). As shown in Table 2, the standard error of CPE spot assay was determined within $10 \%$. When the average of plaque numbers and CPE spot numbers using macrocultures were compared, no differences were shown between the both methods (Table 2). This result shows that CPE spot method without agarose overlay dose not form CPE spots induced by viral multi-infection because of the long period of IHNV replication cycle. These finding satisfied for the quantitative micro assay system using microtiter plates. Practically, as many as 150 CPE spots can be counted in a well of microtiter plates. In the antiviral experiments, it is important to include a "positive virus control" as a standard in each experiment. For the evaluations of candidate, we therefore adopted the concentration of viral inoculum which was shown the CPE spots of the range of 80 to 120 .

In the CPE spot reduction assay, there is a possibility of the difference period of the adsorption in each well, because of operating 96 wells one microtiter plate. For example, we need about $10 \mathrm{~min}$ for IHNV inoculation per one plate. This fact may bring the variation of CPE spot number in each well. In the viral quantitative assay, it is desirable to show a plateau of IHNV adsorption at the period of more than 60 min as reported by BuRKe and Mulcahy. ${ }^{233}$ Therefore, we examined the influence of the adsorption time in CPE spot assay. As can be seen in Fig. 2, the viral adsorption between 60 to 120 min after inoculation of $0.05 \mathrm{ml}$ of virus suspension did not show the plateau. To increase $20 \%$ of CPE spots at adsorption period between 60 to $120 \mathrm{~min}$ offered about $40 \mathrm{~min}$. From this finding, the operation of about $10 \mathrm{~min}$ for the virus inoculation should not affect the CPE spot reduction assay on microtiter plates. However, it is desirable to opperate on a cooling plate for the suppression of the viral adsorption depending on temperature.

The evaluation of CPE spot reduction method was examined by the comparision with the standard plaque reduction method using three compounds having antiviral activity against RNA virus. As shown in Fig. 3, differences between CPE spot reduction method and plaque reduction method were indicated within one-half $\log$ dose of $\mathrm{IC}_{60}$. This finding in not seemed so problem for the evaluation of compounds. When compounds are evaluated by MIC values, a certain compound such as $(S)$-DHPA which shows cytotoxicity in MIC level can not be evaluated correctly by indistinct counting of CPE spots or plaques. So we adopted $\mathrm{IC}_{60}$ value and the profiles of CPE spot reduction curve for the evaluation of compounds. Furthermore, the examination of the reproducibility of CPE spot reduction method showed the reliance of this method (Fig. 4).

From the possibility of the degradation of the compound by certain enzymes presented in FBS, this CPE spot reduction method with three days' incubation is seemed to offer the more convenient 
evaluation than the plaque reduction method with seven days' incubation.

In this report, CPE spot reduction method using microtiter plates was shown to be used for the reliable and quantitative screening of compounds as well as plaque reduction method. Additionally, the three compounds, (S)-DHPA, Virazole and Chloroquine were firstly shown the antiIHNV activity.

The screening of compounds having anti-IHNV activity by the CPE spot reduction method is now in progress.

\section{Acknowledgements}

We would like to thank Dr. Antonin Holy, Czecoslovak Academy of Science, for his kind supply of $(S)$-DHPA. And we would like to thank Professor T. KIMURA, Faculty of Fisheries, Hokkaido University, for his kind supply of IHNV. And we are grateful to Dr. T. SANo, Tokyo University of Fisheries, for his critical reading of the manuscript. This work was supported in part by Grant-in Aid for Cancer Research from Mninistry of Education, Science and Culture of Japan to M. S..

\section{References}

1) K. Wolf: Fish Pathol., 10, 135-154 (1976).

2) W.H. Wingfield, J.L. FrYer, and K.S. PilCher: Proc. Soc. Exp. Biol. Med, 130, 1055-1059 (1969).

3) B. B. Mccain, J. L. Fryer, and K. S. Pilcher: Proc. Soc. Exp. Biol. Med, 146, 630-634 (1974).

4) G. Lenoir, and P. De Kinkelin: J. Virol., 16, 259-262 (1975).

5) P.E. MCALLISTER and R. R. WAGNER：J. Virol., 15, 733-738 (1975).

6) P. E. MCALLISTER and R. R. WAGNER: J. Virol., 22, 839-843 (1977).
7) A. Flamand and J. F. Delagneau: J. Virol, 28, 518-523 (1978).

8) G. D. Coslett, B. P. Holloway, and J. F. OBIJeski: J. Gen. Virol., 49, 161-180 (1980).

9) R. W. Sidwell, J. H. Huffman, G. P. Khare, L. B. ALLEN, J. T. WITKowski, and R. K. RoBINS: Science, 177, 705-706 (1972).

10) H. J. Schaeffer, L. Beauchamp, P. De Miranda, G. B. Elion, D. J. Bauer, and P. Collins: Nature, 272, 583-585 (1978).

11) D. O. Migus and P. Dobos: J. Gen. Virol., 47, 47-57 (1980).

12) M. Savan and P. Dobos: J. Fish Diseases, 3, 437-440 (1980).

13) T. Kimura, S. Suzuki, and M. Yoshimizu: Antiviral Res., 3, 93-101 (1983).

14) T. Kimura, S. Suzuki, and M. Yoshimizu: Antiviral Res., 3, 103-108 (1983).

15) B. B. Godwami and O. K. Sharma: $J$. Virol., 45, 1164-1167 (1983).

16) L. A. Babiuk, S. D. Acres, V. Misra, P. H. G. Stokdale, and E. De Clerce: Antimicroc. Agents Chemother, 23, 715-720 (1983).

17) D.A. EPPSTEIN, Y.V. MARSH, and B.B. SCHRYVER: Virol., 131, 341-354 (1983).

18) R. W. Sidwell and J. H. Huffman: Appl. Microbiol, 22, 797-801 (1971).

19) R. K. Kelly, B. W. Souter, and H. Miller: J. Fish. Res. Board. Can., 35, 1009-1011 (1978).

20) K. Wolf and M. C. QuimgY: Appl. Microbiol., 25, 659-664 (1973).

21) E. De Clerco, J. Descamps, and P. De Somer: Science, 200, 563-564 (1978).

22) J. KaRA, P. VACHA, and A. HolY: FEBS Letters, 107, 187-193 (1979).

23) I. Votruba and A. Holy: Coll. Czech. Chem. Commun., 45, 3039-3044 (1980).

24) M. Shibata, H. Aoki, T. Turumi, Y. Suglura, Y. Nishiyama, S. Suzuki, and K. Maeno: $J$. Gen. Virol., 64, 1149-1156 (1983).

25) J. A. BURKE, and D. MULCAHY: Appl. Environ. Microbiol., 39, 872-876 (1980).

26) P. Dовоs: J. Clin. Microbiol., 3, 373-375 (1976). 